\title{
The Dutch Handedness Questionnaire
}

\author{
Jan W. Van Strien \\ FSW, Department of Psychology, Erasmus University Rotterdam
}

December 2002

\begin{abstract}
Handedness questionnaires typically include an item on preference for writing. However, because writing is influenced by cultural factors, this item was not included in the present 16-item Dutch-language questionnaire. The questionnaire was completed by 456 subjects. The item consistency of the 16 preference items was very high. Principal component analysis on the 16 items revealed one single handedness dimension. Preference for hammering showed the highest item-test correlation. The final version of the handedness inventory contains the ten items with the highest factor loadings.
\end{abstract}

Key Words: handedness; hand preference; sinistrality, ambidexterity; laterality; questionnaire; manual activities

Lateralization of brain function is essential to a broad range of neural and behavioral processes. In the investigation of brain lateralization, handedness is an important subject variable. Research evidence indicates that the patterns of cerebral organization found in left-handers are more heterogeneous than those found in right-handers (Bryden, 1987). Sodium amytal testing and aphasia data have revealed that about $96 \%$ of right-handers have speech mediated by their left hemisphere, and the remaining $4 \%$ have speech mediated by their right hemisphere. For left-handers a distribution is estimated with $60-70 \%$ of lefthanders having left-hemisphere speech, 15-20\% having right hemisphere-speech and $15-20 \%$ having bilateral speech representation (Rasmussen \& Milner, 1977; Segalowitz \& Bryden, 1983).

Two separate aspects of handedness can be discerned. These are proficiency and preference. Proficiency measures refer to the greater muscle-strength and skillfulness of one of the two hands. Muscle strength in each hand can be determined by a test of grip strength; skill of each hand can be assessed by having subjects perform motor tasks, such as finger tapping or Annett's (1985) pegboard task (manipulation of small parts). Preference measures refer to the hand chosen when only one hand is being used in the execution of a given manual activity.

This paper is based on a chapter in my PhD-thesis (Van Strien, 1988). The Dutch Handedness Questionnaire was compiled in collaboration with Anke Bouma, University of Groningen, the Netherlands.

E-mail: vanstrien@fsw.eur.nl 
Preference can be assessed adequately by means of a self-assessment questionnaire in which a subject is asked to indicate which hand is used to throw a ball, to hold a hammer, to draw, and so on.

In general, this type of questionnaires is both reliable and valid (Bryden, 1987). Upon repeated testing, subjects give the same score; and the agreement between actual behavior and the claims on the questionnaire is very high. From the data of Raczkowski, Kalat, and Nebes (1974) 14 hand preference items can be selected, with test-retest agreements ranging from $89-100 \%$ and with test-actual behavior agreements of 93-100\%. Employing an eight-item questionnaire, Porac and Coren (1978) found test-retest agreements (after 12 months) that ranged from 96-100\%.

Neither strength nor skill shows strong concordance with preference. In general, the agreement between preference and proficiency measures equals $59 \%$ for grip strength, $74 \%$ for small parts manipulation, and $80 \%$ for tapping speed (Porac \& Coren, 1981). Comparing proficiency and preference measures, Johnstone, Galin, and Herron (1979) concluded that the handedness questionnaire was the best general measure of handedness. Tapping speed, manipulation of small objects, and grip strength correlated better with the questionnaire than with each other. Compared to the proficiency measures, the questionnaire better related to asymmetry measures based on EEG and dichotic task results. Other studies also have reported low intercorrelations between various skill and strength measures (e.g. Fleischman \& Ellison, 1962). As Porac and Coren have pointed out, the reason for this may be the multidimensional nature of these tasks. Factor analytic studies on proficiency measures have resulted in five to ten separable dimensions (e.g. Barnsley \& Rabinovitch, 1970; Fleischman, 1972). Factors such as strength, speed, coordination, accuracy, and aiming have been found to influence proficiency.

On the other hand, intercorrelations between the items of preference questionnaires are generally very high. For instance, Roszkowski, Snelbecker, and Sacks (1981) assessed the item consistency of 15 preference items and found a Cronbach alpha coefficient that equalled .96. Consistent with this result, Roszkowski et al. reported that factor analysis revealed the presence of only a single dimension. A similar single dimension of handedness has been reported by McFarland and Anderson (1980) and by Richardson (1978).

To summarize, hand preference questionnaires are highly reliable and valid. Because these questionnaires appear to be unifactorial and to relate better to hemispheric laterality than do proficiency measures, the use of these questionnaires may be the most appropriate way to assess handedness.

The three best-known handedness inventories of the last four decades are those of Crovitz and Zener (1962), Annett (1970), and Oldfield (1971). The hand preference items used in these questionnaires, together with 14 selected items of the Raczkowski et al. study, are listed in Table 1. The Crovitz-Zener Questionnaire consists of 14 preference items, with 9 items referring to the preferred hand and the remaining 5 items referring to the nonpreferred hand. These 'reversed' items describe bimanual activities in which the nonpreferred hand is used to position an object in space while the preferred hand is used to manipulate that object. For instance, a right-hander will position a nail with his left hand when hitting it with the hammer in his right hand. It should be noted that the use of reversed items disrupts the homogeneity among the preference items; 
the various items no longer measure one single underlying dimension. Bryden (1977) carried out a factor analysis on 984 completed Crovitz-Zener Questionnaires, and found, besides a handedness factor, a second factor on which the reversed items in particular loaded.

For the present research, a Dutch-language handedness questionnaire was compiled. A selection was made from the most reliable and valid preference items that have been reported for the inventories mentioned above. Two other, not previously used items were also included ("turning a key" and "unscrewing top"). Items of the Crovitz-Zener questionnaire that refer to the use of the nondominant hand were not selected. Items that were ambiguous (such as "top hand on broom") or that referred to gross movements (such as "using glass" and "carrying books") were not selected either. In this paper, the psychometric properties of the questionnaire will be presented.

Table 1: Items from Four Different Handedness Questionnaires.

\begin{tabular}{|c|c|c|c|c|}
\hline & Crovitch and & Annett & Oldfield & Raczkowski, \\
\hline \multicolumn{4}{|l|}{ (1974) } & and Nebes \\
\hline Writing & $\mathrm{x}$ & $\mathrm{x}$ & $\mathrm{x}$ & $\mathrm{x}$ \\
\hline Throwing & $\mathrm{x}$ & $\mathrm{x}$ & $\mathrm{x}$ & $\mathrm{x}$ \\
\hline Holding toothbrush & $\mathrm{x}$ & $\mathrm{x}$ & $\mathrm{x}$ & $\mathrm{x}$ \\
\hline Using scissors & $\mathrm{x}$ & $\mathrm{x}$ & $\mathrm{x}$ & $\mathrm{x}$ \\
\hline Draw & $\mathrm{x}$ & & $\mathrm{x}$ & $\mathrm{x}$ \\
\hline Holding racket & $\mathrm{x}$ & $\mathrm{x}$ & & $\mathrm{x}$ \\
\hline Striking a match & & $\mathrm{x}$ & $\mathrm{x}$ & $\mathrm{x}$ \\
\hline Dealing cards & & $\mathrm{x}$ & & $\mathrm{x}$ \\
\hline Holding hammer & & $\mathrm{x}$ & & $\mathrm{x}$ \\
\hline Holding eraser & & & & $\mathrm{x}$ \\
\hline Using butte opener & & & & $\mathrm{x}$ \\
\hline Using screwdriver & & & & $\mathrm{x}$ \\
\hline Top hand on broom & & $\mathrm{x}$ & $\mathrm{x}$ & \\
\hline Treading needle & & $\mathrm{x}$ & & \\
\hline Top hand on shovel & & $\mathrm{x}$ & & \\
\hline Cutting with a knife & $\mathrm{x}$ & & $\mathrm{x}$ & \\
\hline Opening a box & & & $\mathrm{x}$ & \\
\hline Pouring a pitcher & $\mathrm{x}$ & & & \\
\hline Unscrewing jar lid & & $\mathrm{x}$ & & \\
\hline Carrying books & & & & $\mathrm{x}$ \\
\hline Using a glass & $\mathrm{x}$ & & & \\
\hline Using spoon & & & $\mathrm{x}$ & \\
\hline Stirring & & & & $\mathrm{x}$ \\
\hline \multicolumn{5}{|l|}{ Reversed items: } \\
\hline Holding a nail for & & & & \\
\hline hammering & $\mathrm{x}$ & & & \\
\hline Holding a bottle to & & & & \\
\hline uncap it & $\mathrm{x}$ & & & \\
\hline Holding a potato to & & & & \\
\hline peel it & $\mathrm{x}$ & & & \\
\hline Holding a needle to & & & & \\
\hline thread it & $\mathrm{x}$ & & & \\
\hline Holding a dish to & & & & \\
\hline wipe it & $\mathrm{x}$ & & & \\
\hline
\end{tabular}




\section{METHOD}

\section{Self-assessment questionnaire}

The self-assessment handedness questionnaire consisted of 16 hand preference items. The items are listed in table 2. For each activity in the questionnaire the subjects indicated whether the left or right hand was used or whether both hands were used.

Table 2: Items Contained in the Handedness Questionnaire.

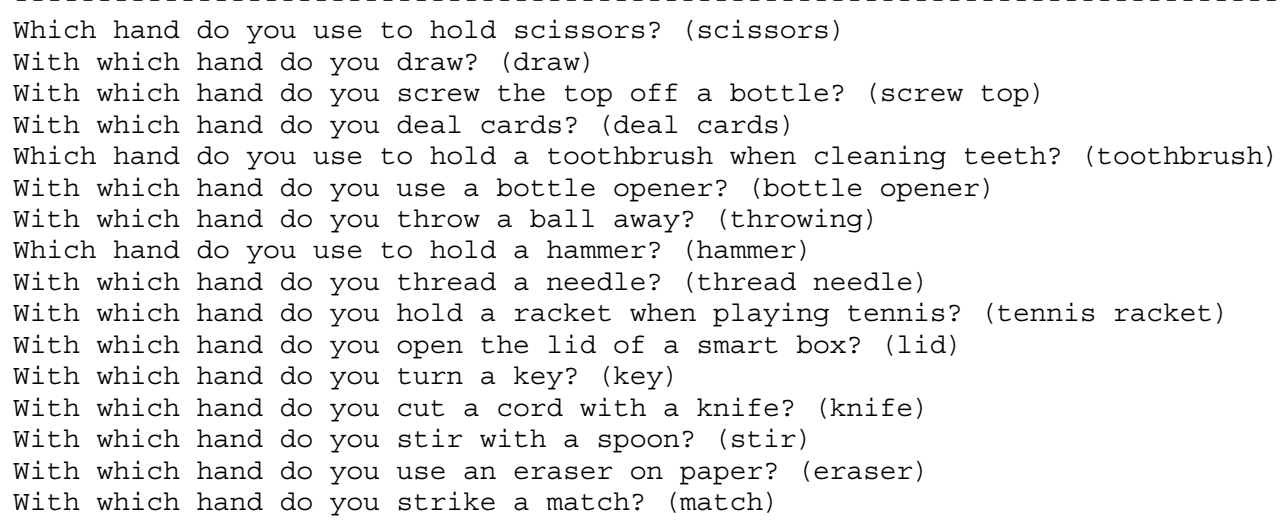

They received the following written instruction:

"A number of activities, in which you can use either your left or your right hand, are specified below. Indicate which hand you usually use for these activities. Visualize the activity in question, if you are not immediately sure of an answer. If you don't have a clear preference, indicate that you use both hands."

Each item was coded from 0 to 2, with "left" receiving a score of 0 and "right" receiving a score of 2 , and "both" receiving a score of 1 . Therefore, the total score could range from 0 (i.e. extremely left-handed) to 32 (i.e. extremely righthanded). Subjects also had to indicate which hand they used for writing and to report whether they had been compelled to use the non-preferred hand for writing. Note that writing hand was not included as a preference item, because writing is thought to be more influenced by cultural factors than are any of the other manual activities.

\section{Participants}

Completed questionnaires were obtained from 456 persons (213 male, 243 female), mainly students as well as a number of university staff members, who had been recruited through university newspaper advertisements. In these advertisements, left-handers in particular were asked to participate. About $54 \%$ of both male and female respondents used their left hand for writing and about $46 \%$ used 
their right hand. Ages ranged from 16 to 45 years, with a mean age of 24 years. Note that the present sample is not representative of the general population with respect to the prevalence of left-handedness. However, in a true population sample with a relatively small number of left-handers, scores would be extremely skewed to the right.

Table 3: 1tem-Rest Correlations.

$\begin{array}{ll}\text { Activity } & \begin{array}{c}\text { Item-Rest } \\ \text { Correlation }\end{array} \\ \text { Hammer } & .94 \\ \text { Stir } & .93 \\ \text { Eraser } & .93 \\ \text { Match } & .93 \\ \text { Knife } & .93 \\ \text { Toothbrush } & .92 \\ \text { Bottle Opener } & .92 \\ \text { Tennis Racket } & .91 \\ \text { Draw } & .89 \\ \text { Throwing } & .88 \\ \text { Key } & .85 \\ \text { Lid } & .80 \\ \text { Deal Cards } & .79 \\ \text { Thread Needle } & .76 \\ \text { Scissors } & .74 \\ \text { Screw Top } & .72\end{array}$

\section{RESULTS}

\section{Item analysis}

Each handedness item was correlated with the total score minus the particular item (item-rest correlation). The item-rest correlation coefficients are presented in Table 3 . The item that had the highest correlation with the total score was using a hammer, followed by stirring, erasing, striking a match, and cutting with a knife. The lowest correlations were found for dealing cards, threading a needle, holding scissors and unscrewing a top. The item consistency, as measured by Cronbach's homogeneity coefficient alpha, was very high: .98.

\section{Principal component analysis}

Because we selected items that supposedly measured a single dimension, we examined whether this was the case by means of a principal component analysis. One single factor was found, having an eigenvalue of 12.5 and accounting for $78.4 \%$ of the variance. The factor loadings and communalities of the 16 hand preference items on this factor are listed in Table 4. 
Table 4: Factor loadings and Communalities on the Handedness Factor.

$\begin{array}{lcc}\text { Activity } & \text { Loading } & \text { Communality } \\ \text { Hammer } & .95 & .90 \\ \text { Eraser } & .95 & .89 \\ \text { Stir } & .94 & .89 \\ \text { Match } & .94 & .89 \\ \text { Knife } & .94 & .88 \\ \text { Toothbrush } & .94 & .88 \\ \text { Bottle Opener } & .93 & .87 \\ \text { Tennis Racket } & .92 & .85 \\ \text { Draw } & .91 & .83 \\ \text { Throwing } & .90 & .81 \\ \text { Key } & .87 & .67 \\ \text { Lid } & .82 & .66 \\ \text { Deal Cards } & .81 & .62 \\ \text { Thread Needle } & .79 & .60 \\ \text { Scissors } & .77 & .56 \\ \text { Screw Top } & .75 & \\ \text { - } & & .-1-\ldots\end{array}$

Table 5: Percentage of Strongly Left-handed Subjects, Ambidexters and Strongly Right-handed Subjects Using Left Hand, Both Hands, or Right Hand for Each Activity.

\begin{tabular}{|c|c|c|c|}
\hline & Strongly & $\begin{array}{l}\text { Left-handed } \\
\quad(\mathrm{n}=184)\end{array}$ & bjects \\
\hline Activity & Left & Both & Right \\
\hline \multicolumn{4}{|c|}{ 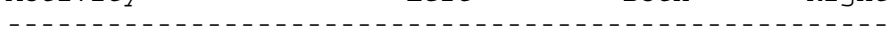 } \\
\hline Writing & 92.3 & 0.5 & 7.1 \\
\hline Scissors & 82.6 & 2.7 & 14.7 \\
\hline Draw & 96.7 & 1.1 & 2.2 \\
\hline Screw Top & 91.8 & 3.8 & 4.3 \\
\hline Deal Cards & 95.1 & 0.5 & 4.3 \\
\hline Toothbrush & 95.1 & 3.8 & 1.1 \\
\hline Bottle Opener & 98.9 & 0.5 & 0.5 \\
\hline Throwing & 97.8 & 0.0 & 2.2 \\
\hline Hammer & 100.0 & 0.0 & 0.0 \\
\hline Thread Needle & 89.7 & 2.7 & 7.6 \\
\hline Tennis Racket & 98.4 & 0.0 & 1.6 \\
\hline Lid & 94.6 & 3.8 & 1.6 \\
\hline Key & 90.8 & 6.5 & 2.7 \\
\hline Knife & 98.9 & 0.5 & 0.5 \\
\hline Stir & 96.2 & 3.3 & 0.5 \\
\hline Eraser & 99.5 & 0.0 & 0.5 \\
\hline Match & 99.5 & 0.0 & 0.5 \\
\hline \multicolumn{4}{|c|}{$\begin{array}{c}\text { Ambidexters } \\
\text { (n }=101 \text { ) }\end{array}$} \\
\hline Activity & Left & Both & Right \\
\hline \multicolumn{4}{|c|}{ 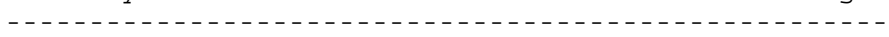 } \\
\hline Writing & 73.0 & 0.0 & 27.0 \\
\hline Scissors & 32.0 & 5.0 & 64.0 \\
\hline Draw & 81.0 & 1.0 & 18.0 \\
\hline Screw Top & 39.0 & 18.0 & 43.0 \\
\hline Deal Cards & 53.0 & 7.0 & 40.0 \\
\hline Toothbrush & 67.0 & 12.0 & 21.0 \\
\hline Bottle Opener & 59.0 & 12.0 & 29.0 \\
\hline Throwing & 54.0 & 3.0 & 43.0 \\
\hline
\end{tabular}


Table 5 (continued)

Ambidexters

\begin{tabular}{|c|c|c|c|}
\hline \multirow{2}{*}{ Activity } & Left & Both & Right \\
\hline & ---- & ---- & ----- \\
\hline Hammer & 63.0 & 7.0 & 30.0 \\
\hline Thread Needle & 67.0 & 7.0 & 26.0 \\
\hline \multirow{2}{*}{$\begin{array}{l}\text { Tennis Racket } \\
\text { Lid }\end{array}$} & 54.0 & 8.0 & 38.0 \\
\hline & 51.0 & 26.0 & 23.0 \\
\hline Key & 30.0 & 30.0 & 40.0 \\
\hline Knife & 60.0 & 5.0 & 35.0 \\
\hline Stir & 61.0 & 18.0 & 21.0 \\
\hline \multirow{2}{*}{$\begin{array}{l}\text { Eraser } \\
\text { Match }\end{array}$} & 75.0 & 13.0 & 12.0 \\
\hline & 60.0 & 13.0 & 27.0 \\
\hline \multicolumn{4}{|c|}{$\begin{array}{r}\text { Strongly Right-handed Subjects } \\
(\mathrm{n}=172)\end{array}$} \\
\hline Activity & Left & Both & Right \\
\hline \\
\hline \multicolumn{4}{|c|}{$\begin{array}{llll}\text { Writing } & 1.2 & 0.6 & 98.2\end{array}$} \\
\hline Scissors & 0.0 & 0.0 & 100.0 \\
\hline Draw & 1.2 & 0.0 & 98.8 \\
\hline Screw Top & 8.7 & 5.2 & 86.0 \\
\hline Deal Cards & 2.3 & 2.3 & 95.3 \\
\hline Toothbrush & 0.0 & 0.6 & 99.4 \\
\hline \multirow{2}{*}{$\begin{array}{l}\text { Bottle Opener } \\
\text { Throwing }\end{array}$} & 0.6 & 2.3 & 97.1 \\
\hline & 0.0 & 0.6 & 99.4 \\
\hline Hammer & 0.6 & 0.0 & 99.4 \\
\hline Thread Needle & 6.4 & 2.9 & 90.7 \\
\hline \multirow{2}{*}{$\begin{array}{l}\text { Tennis Racket } \\
\text { Lid }\end{array}$} & 0.0 & 0.0 & 100.0 \\
\hline & 2.9 & 15.7 & 81.4 \\
\hline Key & 0.0 & 2.9 & 97.1 \\
\hline Knife & 0.0 & 0.6 & 99.4 \\
\hline Stir & 0.0 & 5.2 & 94.8 \\
\hline Eraser & 0.6 & 1.2 & 98.3 \\
\hline Match & 0.0 & 0.6 & 99.4 \\
\hline
\end{tabular}

Given the single handedness dimension, it is no surprise that the results are highly similar to the outcomes of the item analysis. The highest loadings on the handedness factor were found for using a hammer, stirring, erasing, striking a match and cutting, with a knife.

\section{Handedness groups}

The use of a self-assessment hand preference questionnaire allows for the measurement of handedness along a continuum. Subjects who perform all activities with their left hand represent one end of the continuum, while subjects who perform all activities with the right hand represent the opposite end. A frequently used subdivision into three handedness groups is: (1) strongly left-handed subjects, (2) ambidexters, and (3) strongly right-handed subjects. In the present research, subjects are considered to be strongly left-handed if their total score on the questionnaire equalled four or less, or to be strongly right-handed if this score equalled 28 or more. Based on these criteria, our subjects were assigned to the three handedness groups. Subsequently, hand preferences for writing and the other activities listed in the questionnaire were examined in each group. The results are given in Table 5. As can be seen from this table, the vast majority of the strongly left- and right-handed subjects used their preferred hand for the listed activities. However a substantial part of the strongly left-handed subjects (15\%) held scissors in the right hand. This may be due to the fact that scissors usually 
are designed for right-handers. About $7 \%$ of the strongly left-handed subjects used their right hand for writing. It is remarkable that only $2 \%$ of the strongly lefthanded subjects used their right hand for drawing. Apparently, a number of lefthanders have been forced to use their right hand for writing but have been allowed to use their left hand for drawing.

The prevalence of individuals who reported to use both hands for a certain activity was larger in the group of ambidexters than in the two other groups. Yet, a large proportion of the ambidexters used either the left or the right hand for a particular activity. It therefore seems likely that persons with an ambiguous hand preference (i.e., persons who show no clear preference for a given hand on most of the tasks) accounted for only a minority of the group of ambidexters. In the group of ambidexters, $27 \%$ used the right hand for writing, while $18 \%$ used this hand for drawing. This result again demonstrates the cultural influence on the choice of the writing hand. Surprisingly, two strongly right-handed individuals used their left hand for writing and drawing.

\section{CONCLUSIONS}

Both the item-consistency measure and the principal component analysis clearly proved that the items of the questionnaire at issue assessed one single handedness dimension. Hammering and erasing were the items with the highest loadings on this handedness factor. Other studies also have found hammering to be the best single predictor of handedness (Annett, 1970; Roszkowski et al, 1981). Hammering demands exact motor control; each blow requires precise aiming, timing and modulation of force. Obviously, if one mishits a nail, the results can be disastrous. Most likely, the best strategy is to use the preferred hand for hammering and to never try the nonpreferred hand.

When asked, $8 \%$ of the respondents in the present sample indicated that in childhood they had been compelled to use the right hand for writing instead of the preferred left hand. The questionnaire data indicated that about $6 \%$ of the lefthanders and ambidexters use the right hand for writing and the left hand for drawing. It is evident that for a number of left-handers the choice of writing hand bas been influenced by culture. Therefore, it seems justified that in the present questionnaire writing is not included as a preference item.

For practical use, a shorter version of the handedness questionnaire can be constructed easily by selecting the 10 items with the highest factor loadings (See appendix 1 for the final 10-item Dutch-language version.)

\section{REFERENCES}

Annett, M. (1970). A classification of handpreference by association analysis. British Journal of Psychology, 61, 303-321.

Annett, M. (1985). Left, right, hand and brain: The right shift theory. London. Erlbaum.

Barnsley, R.H., \& Rabinovitch. M.S. (1970). Handedness: Proficiency versus stated preference. Perceptual and Motor Skills, 30, 343-362. 
Bryden, M.P. (1987). Handedness and cerebral organization: Data from clinical and normal populations. In D. Ottoson (Ed.), Duality and unity of the brain, (pp. 55-70). Houndmills: Macmillan Press.

Crovitz, H.F., \& Zener, K. (1962). A group-test for assessing hand- and eyedominance. American Journal of Psychology, 75, 271-276.

Fleischman, E.A. (1972). On the relation between abilities, learning and human performance. American Psychologist, 27, 1017-1032.

Fleischman, E.A., \& Ellison, G.D. (1962). A factor analysis of five manipulative tests. Journal of Applied Psychology, 46, 96-105.

Johnstone, J., Galin, D., \& Herran, J. (1979). Choice of handedness measures in studies of hemispheric specialization. International Journal of Neuroscience, 9, 71 -80.

McFarland, K., and Anderson, J. (1980). Factor stability of the Edinburgh Handedness Inventory as a function of test-retest performance, age and sex. British Journal of Psychology, 71, 135-142.

Oldfield, R.C. (1971). The assessment and analyses of handedness: The Edinburgh inventory. Neuropsychologia, 9, 97-113.

Porac, C., \& Coren, S. (1978). Relationships among lateral preference behaviors in human beings. Behavioral and Brain Sciences, 2, 311-312.

Porac, C., \& Coren, S. (1981). Lateral preferences and human behavior. New York: Springer Verlag.

Raczkowski, D., Kalat, J.W., \& Nebes, R. (1974). Reliability and validity of some handedness questionnaire items. Neuropsychologia, 12, 43-47.

Rasmussen,T., \& Milner, B. (1977). The role of early left-brain injury in determining lateralization of cerebral speech functions. Annals of the New York Academy of Sciences, 299, 355-369.

Richardson, J.T.E. (1978). A factor analysis of self-reported handedness. Neuropsychologia, 16, 747-748.

Roszkowski, M.J., Snelbecker G.E., \& Sacks, R. (1981). Children's, adolescents', and adults' reports of hand preference: Homogeneity and discriminating power of selected tasks. Journal of Clinical Neuropsychology, 3, 199-213.

Segalowitz, S.J., \& Bryden, M.P. (1983). Individual differences in hemispheric representation. In S. J. Segalowitz Ed., Language functions and brain organization (pp. 341-372). New York: Academic Press. 
Van Strien, J.W. (1988). Handedness and hemispheric laterality. Thesis, Vrije Universiteit Amsterdam, the Netherlands. 
APPENDIX - Dutch Handedness Questionnaire

\section{Dutch Handedness Questionnaire}

\section{Jan W. Van Strien - Erasmus University Rotterdam}

With this questionnaire you can measure the extent of your left- or righthandedness. This questionnaire contains one question about the hand you preferentially use for writing and ten questions about your hand preference for other activities.

\section{Writing hand}

Circle which hand you use for writing: left / right / forced to use the right hand in school

\section{Hand preference}

Below, a number of activities are listed that you can perform with either your left or right hand. Indicate which hand you usually use for each of these activities. If you do not immediately know the answer, imagine performing the activity. Only if you have no clear preference, circle 'both'

1 Which hand do you use to draw?

2. Which hand do you use to brush your teeth?

3. Which hand do you use to hold a bottle opener?

4. Which hand do you use to throw a ball far away?

5. Which hand do you use to hammer a nail?

6. Which hand do you use to hold a (tennis) racket?

7. Which hand do you use to hold a knife when cutting a rope?

8. Which hand do you use to stir with a spoon?

9. Which hand do you use to hold an eraser when rubbing out something?

10. Which hand do you use to hold a match while striking it? left / right / both left / right / both left / right / both left / right / both left / right / both left / right / both left / right / both left / right / both left / right / both left / right / both

\section{Scoring}

Left $=-1$, right $=+1$, both $=0$.

The score varies from -10 for extreme left-handedness to +10 for extreme righthandedness.

\section{Reference}

Van Strien, J.W. (1992). Classificatie van links- en rechtshandige proefpersonen. [Classification of left- and right-handed research participants]. Nederlands

Tijdschrift voor de Psychologie, 47, 88-92. 